\title{
Endoscopic closure of transmural esophageal perforation after balloon dilation for achalasia
}

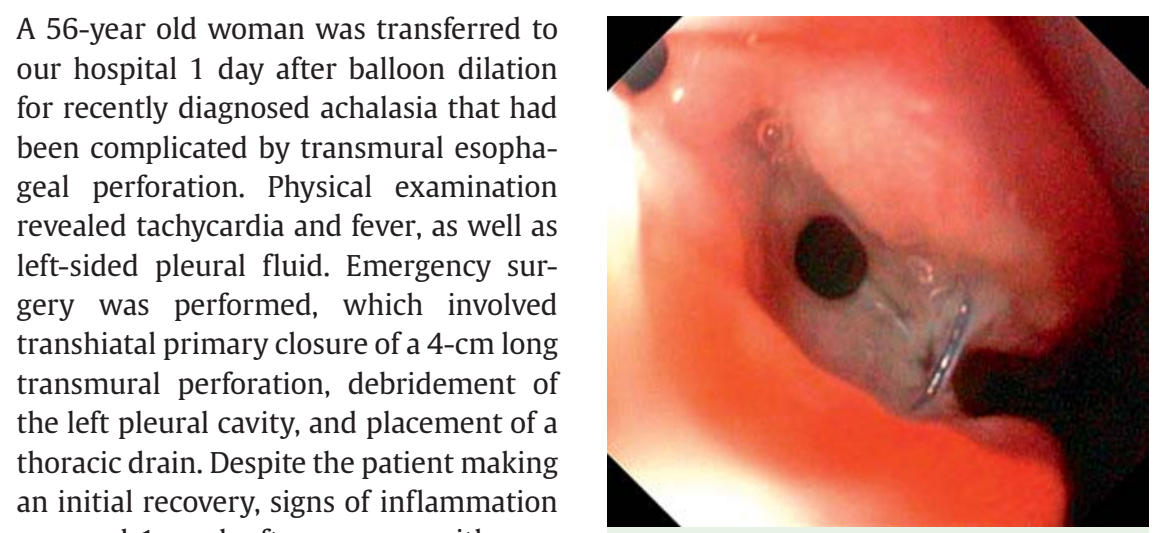
recurred 1 week after surgery, with production of increased fluid via the drain.

Esophagogastroduodenoscopy revealed the surgical sutures just proximal to the esophagogastric junction and at least two locations where these sutures had given way resulting in recurrent perforation $(\bullet$ Fig. 1). Clipping was considered unlikely to be helpful because of the size of the perforation. Stent placement was not considered to be a useful option because of the wide diameter of the esophagus. Therefore, an over-the-scope clip (OTSC, Ovesco Endoscopy GmbH, Tübingen, Germany) was deployed to close the perforation ( Fig.2). Subsequent application of methylene blue did not result in staining of the drainage fluid, which suggested immediate complete closure had been achieved. The thoracic drain was able to be removed 1 week after the endoscopic procedure, and oral intake was reinstated after a barium swallow showed no leakage of contrast medium. The patient was discharged in a good clinical condition 10 days after the procedure.

Esophageal perforation occurs in approximately $2 \%$ of balloon dilations being performed for achalasia [1]. Nonsurgical management is feasible, with favorable short-term and long-term outcomes, but in our patient severe systemic inflammation required closure of the perforation and debridement of the pleural space [2]. The OTSC system has been developed for treatment of gastrointestinal bleeding and colonic perforations [3]. Recently, its
Fig. 1 Endoscopic view of the esophagus showing the perforations left following unsuccessful emergency surgery to close the defects previously produced by balloon dilation for achalasia. The surgical sutures had given way in at least two locations, resulting in recurrent perforation.

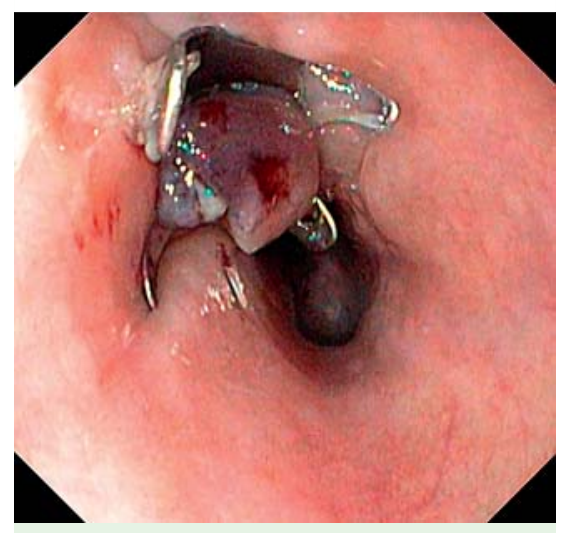

Fig. 2 Endoscopic view of the perforation site showing the deployed over-the-scope clip in position.

use in postoperative esophageal leaks has been described as well $[4,5]$. This clipping device is relatively easy to use and may play an important role in primary closure of (iatrogenic) gastrointestinal perforations, as well as being a second-line treatment after failed surgical therapy.

\section{Endoscopy_UCTN_Code_TTT_1AO_2AI}

\section{Competing interests: None}

S. J. B. Van Weyenberg ${ }^{1}$, N. K de Boer ${ }^{1}$, B. M. Zonderhuis ${ }^{2}$, D. L. van der Peet ${ }^{2}$

${ }^{1}$ Department of Gastroenterology and Hepatology, VU University Medical Centre, Amsterdam, The Netherlands

2 Department of Surgery, VU University Medical Centre, Amsterdam, The Netherlands

\section{References}

1 Katzka DA, Castell DO. Review article: an analysis of the efficacy, perforation rates and methods used in pneumatic dilation for achalasia. Aliment Pharmacol Ther 2011; 34: $832-839$

2 Vanuytsel T, Lerut T, Coosemans $W$ et al. Conservative management of esophageal perforations during pneumatic dilation for idiopathic esophageal achalasia. Clin Gastroenterol Hepatol 2012; 10: 142 - 149

3 Kirschniak A, Kratt T, Stuker D et al. A new endoscopic over-the-scope clip system for treatment of lesions and bleeding in the GI tract: first clinical experiences. Gastrointest Endosc 2007; 66: 162-167

4 PohlJ, Borgulya M, Lorenz D et al. Endoscopic closure of postoperative esophageal leaks with a novel over-the-scope clip system. Endoscopy 2010; 42: 757-759

5 Hagel AF, Naegel A, Lindner AS et al. Overthe-scope clip application yields a high rate of closure in gastrointestinal perforations and may reduce emergency surgery. J Gastrointest Surg 2012; 16: 2132-2138

\section{Bibliography}

Dol http://dx.doi.org/

10.1055/s-0032-1326257

Endoscopy 2013; 45: E88

(c) Georg Thieme Verlag KG

Stuttgart · New York

ISSN 0013-726X

\section{Corresponding author}

\section{S. J. B. Van Weyenberg, MD}

Department of Gastroenterology and Hepatology

VU University Medical Centre

De Boelelaan 1118

1081 HV Amsterdam

The Netherlands

Fax: +31-20-4440554

sjb.vanweyenberg@vumc.nl 